\title{
LIFE ANNUITIZATION: WHY AND HOW MUCH?
}

BY

\author{
Donatien Hainaut and Pierre Devolder
}

\begin{abstract}
This paper addresses some of the problems a majority of retired individuals face: Why and in what proportion should they invest in a life annuity to maximize the utility of their future consumption or a bequest? The market considered in this work is made up of three assets: a life annuity, a risky asset and a cash account. As this problem doesn't accept any suitable explicit solution, it is numerically solved by the Markov Chain approximation developed by Kushner and Dupuis. Without a bequest motive, we observe that the optimal planning of consumption is divided into two periods and that optimal asset allocation should include the risky asset. Next, the influence of a bequest on consumption and investment pattern is developed. We demonstrate that even with a bequest motive, pensioners should allocate a part of their wealth to the purchase of life annuities.
\end{abstract}

\section{KEYWORDS}

Optimal consumption and portfolio policies, annuity puzzle, Markov chain approximation, stochastic control.

\section{INTRODUCTION}

This paper addresses the optimal individual asset allocation problem, at the age of retirement, between classical financial investments and life annuities. Even if it is generally accepted that life annuities are an efficient insurance against a decrease of the standard of living, the success of such products is still limited. However, in recent years, life annuitization has become an interesting option for individuals on retirement. One argument pleading in favour of annuitization is the huge volatility of alternative investments such as those currently available on financial markets and the low return of state bonds ${ }^{1}$. In comparison, a life

1 For example, in Belgium, the $10 \mathrm{Y}$ bond yield reached $8.5 \%$ in 1994 whereas the guarantee embedded in the annuity was limited to a maximum of $4.75 \%$ by the regulator. Over ten years, this gap has substantially fallen: since 2004 , the $10 \mathrm{Y}$ yield has oscillated between $3 \%$ and $4 \%$ whereas the annuity guarantee now is legally bounded at $3.25 \%$ 
annuity is an interesting choice because of its longevity protection, coupled with an interest rate guarantee which is a long term protection against financial setbacks. This work introduces a model providing rational arguments in favour of the integration of life annuity in the individuals asset allocation as a pensioner who wishes to maximize the utility arising from both its consumption and from a bequest to relatives.

The issue of optimal individual asset allocation at retirement, also known as the annuity puzzle, is widely studied in the actuarial and social literature. We mention here papers motivating this work. The starting point of our research is the seminal paper of Yaari (1965), which has proved that a person, without a bequest motive and under certain assumptions, should prefer a full annuitization in a market without any risky asset. An intuitive proof of this result is that the rate of return of an annuity is always higher than the risk free rate, because it includes a mortality risk credit. The dynamic programming approach, applied by Merton to consumption/investment issues $(1969,1971)$ was then extended by Richard (1975) to describe the optimal behaviour of an individual throughout his lifetime, in the presence of deterministic incomes. Merton (1983) has considered consumption-linked benefits, which could be financed by a consumption tax or by the yield of assets with returns linked to consumption. Kapur and Orszag's paper (1999) focuses on the pensioner's portfolio strategy with pure endowments. Milevsky $(1998,2001)$ and Young (2000) have developed a model in which the individual defers the purchase of a life annuity until it is not possible to beat the rate of return of an annuity. Davidoff et al. (2003) have proved that full annuitization is optimal in a more general setting than Yaari's. Blake et al. (2003) compared three different static strategies of consumption and investment with and without a bequest motive in a market proposing equity-linked annuities. Lachance (2003) studied how a worker's ability to take investment risk is influenced by his capacity to adjust his retirement date as a function of market fluctuations. Purcal and Pigott (2004) calibrated the Richard's model to the Japanese market in order to explain the demand in life annuity. An extension of Richard's model to stochastic incomes is numerically solved by Purcal (2004). Another attempt of calibration of Yaari's model to the U.S. market was done by Petrova (2004). Finally, we refer to Devolder and Hainaut (2005) for the treatment of a similar issue by a Lagrangian approach, in a deterministic market.

This paper introduces a numerical method solving the pensioner's asset allocation problem. We assume that he can invest his capital in life annuity and in the financial market made up of cash and of a risky asset. Decision about the annuitized amount is made once for all at the age of retirement. Our aim is to determine both optimal investment and consumption strategies, which maximize the expected utility drawn from future consumption and eventually from a future bequest to relatives. After formulation of the problem, we presented the Hamilton Jacobi Bellman (HJB) equation coupled with this stochastic control problem and solved it numerically. We adapted Kushner and Dupuis' method (2001) and have developed an iterative algorithm. The main technical 
difficulties consist of the choice of parameters of discretization to ensure the convergence of the algorithm.

The main results of this paper are summarized as follows. For an individual without a bequest motive, a small fraction of the capital should be dedicated to the purchase of risky assets. His optimal consumption pattern can be subdivided into two periods. During the first one, he will consume the entire annuity and a part of his wealth. Beyond a certain age, the consumption is equal to the annuity and his savings are depleted. An interesting observation is that optimal asset allocation still includes a life annuity if the retiree wishes to pass on a bequest to his relatives. The optimal investment strategy is in agreement with the generally admitted principle that: the quantities of risky assets decrease with age.

The outline of this paper is as follows. In section 2, we introduce the general model of optimal consumption and the related HJB equation. Section 3 develops a numerical method based on the implicit discretisation of the HJB equation. In section 4 , we have applied this methodology to the optimal choice without a bequest motive; similarly, section 5 is devoted to the case bearing a bequest motive. Section 6 finalizes this paper.

\section{THE MARKET AND THE INDIVIDUAL'S MAXIMIZATION PROBLEM}

We consider the case of an individual who retires at age $x$ and has to allocate his wealth, noted $W_{0}$, between a cash account, a risky asset (equities) and a life annuity. The amount annuitized is chosen once and for all at the age of retirement. Let $\alpha$ be a fraction of the initial capital devoted to the purchase of a continuous annuity, $B_{x}$ (the annuity rate is indexed by $x$ because it depends on the pensioner's age at the time of contract subscription). The remaining capital is managed by the pensioner and invested in a fund of cash and equities. This fund is noted $F_{0}=(1-\alpha) . W_{0}$. The life annuity rate $B_{x}$ is constant and calculated by the classical actuarial formula:

$$
B_{x}=\frac{\alpha \cdot W_{0}}{\bar{a}_{x, x+T}} \cdot \frac{1}{1+\varepsilon}
$$

\section{Where:}

- $\varepsilon$ : commercial loading.

- $\bar{a}_{x, x+T}=\int_{x}^{x+T} e^{-r^{t f} \cdot(s-x)} \cdot{ }_{s-x} p_{x}^{t f} \cdot d s$ is a continuous life annuity from age $x$ to age $x+T \cdot r^{t f}$ is the interest rate granted to the customer and ${ }_{u} p_{x}^{t f}$ is the survival probability from age $x$ to age $x+u$. T is statistically the maximum age that a human being could reach.

- ${ }_{u} p_{x}^{t f}=e^{-\int_{0}^{u} \mu^{t f}(x+z) d z}$ where $\mu^{t f}(t)$ is the mortality rate of the tariff. The real survival probability and the associated mortality rate are each respectively noted ${ }_{u} p_{x}$ and $\mu(t)$. They will be used later in the formulation of the problem. 
The individual has access to a financial market made up of two assets, cash and equities, respectively noted $S_{0}$ and $S_{1}$, with the following dynamics:

$$
\begin{aligned}
& d S_{0}=S_{0} \cdot r \cdot d t \\
& d S_{1}=S_{1} \cdot m \cdot d t+S_{1} \cdot \sigma \cdot d W_{t}
\end{aligned}
$$

The risk free rate $r$, the expected return of equities $m$ and the volatility $\sigma$ are constant. $\left(W_{t}\right)_{0 \leq t}$ is a Brownian motion defined on a probability space $(\Omega, \mathcal{F}, \mathbb{P})$ where $\left(\mathcal{F}_{t}\right)_{0 \leq t}$ is the natural filtration of $W_{t}$. The fund at time $t$ is noted $F_{t}$ and the fraction of $F_{t}$ invested in equities is noted as $\pi_{t}$. Consumption by the individual at time $t$ is noted $c_{t}$. The dynamic of the savings managed by the individual is the sum of the financial return on investments and of the gap between annuity and consumption rates:

$$
d F_{t}=\underbrace{\left(1-\pi_{t}\right) \cdot F_{t} \cdot \frac{d S_{0}}{S_{0}}+\pi_{t} \cdot F_{t} \cdot \frac{d S_{1}}{S_{1}}}_{\text {financial return }}+\underbrace{\left(B_{x}-c_{t}\right) \cdot d t}_{\text {annuity - consumption }}
$$

Combining this last equation with (2) and (3), we obtain the following SDE for the individual's savings

$$
d F_{t}=\left(\left(r+\pi_{t} \cdot(m-r)\right) \cdot F_{t}-c_{t}+B_{x}\right) \cdot d t+\pi_{t} \cdot F_{t} \cdot \sigma \cdot d W_{t}
$$

The dynamic of the wealth being established; we will now define the objective of the pensioner. Let $U_{1}\left(c_{t}\right)$ and $U_{2}\left(F_{t}\right)$ be respectively the utility provided by consumption and the utility of the bequest of $F_{t}$, if the individual deceases at time $t$. We assume that those utilities are C.R.R.A, with risk aversion parameters $\gamma_{i=1,2}<1$ :

$$
U_{1}\left(c_{t}\right)=\frac{c_{t}^{\gamma_{1}}}{\gamma_{1}} \quad U_{2}\left(F_{t}\right)=u_{2} \cdot \frac{F_{t}^{\gamma_{2}}}{\gamma_{2}}
$$

$u_{2}$ is a parameter that is worth 0 if the individual has no bequest motives. Otherwise $u_{2}$ can take any positive value depending on the strength of the bequest motive. The objective pursued by the pensioner at time $t$, is to determine the consumption and investment patterns hence maximizing his total expected utility. If $\tau$ is the random instant of death, and $\rho$ is a discount factor corresponding to the rush to consume, the value function at time $t$, is defined by:

$$
v\left(F_{t}, t\right)=\max _{c_{t}, \pi_{t} \in \mathbb{U}} \mathbb{E}\left(\int_{t}^{\tau} e^{-\rho \cdot(s-t)} \cdot U_{1}\left(c_{s}\right) \cdot d s+e^{-\rho \cdot(\tau-t)} \cdot U_{2}\left(F_{\tau}\right) \mid \mathcal{F}_{t}\right)
$$

Where $\mathbb{U}$ is the set of admissible strategies:

$$
\mathbb{U}=\left\{c_{t}, \pi_{t}: F_{t} \geq 0 \quad \pi_{t} \leq \pi_{b} \quad \forall t \in[0, \tau]\right\}
$$


The set $\mathbb{U}$ is delimited by a constraint on wealth, stipulating that wealth may not be negative and by a constraint on investments, specifying that the position in risky assets has an upper bound. This bound is usually set to $100 \%$ because a short position in cash is not allowable for an individual saver. We refer to Richard (1975) to demonstrate that the equation (5) is equivalent to:

$v\left(F_{t}, t\right)=\max _{c_{t}, \pi_{t} \in \mathbb{U}} \mathbb{E}\left(\int_{t}^{T} e^{-\rho \cdot(s-t)} \cdot_{s-t} p_{x+t} \cdot\left(U_{1}\left(c_{s}\right)+\mu(x+s) \cdot U_{2}\left(F_{s}\right)\right) \cdot d s \mid \mathcal{F}_{t}\right)$

From the theory of stochastic control (e.g. Fleming and Rishel 1975), we know that the value function for a given wealth $f$ is solution of the HJB:

$$
\begin{aligned}
0= & \frac{\partial v(f, t)}{\partial t}-(\rho+\mu(x+t)) \cdot v(f, t)+ \\
& \sup _{c_{t}, \pi_{t} \in \mathbb{U}}\left(L^{c_{t}, \pi_{t}} v(f, t)+\frac{c_{t}^{\gamma_{1}}}{\gamma_{1}}+\mu(x+t) \cdot u_{2} \cdot \frac{f^{\gamma_{2}}}{\gamma_{2}}\right)
\end{aligned}
$$

Where $L^{c_{t}, \pi_{t}} v(f, t)$ is the infinitesimal generator of $v(f, t)$ :

$$
\begin{aligned}
L^{c_{t}, \pi_{t}} v(f, t)= & \left(\left(r+\pi_{t} \cdot(m-r)\right) \cdot f+B_{x}-c_{t}\right) \cdot \frac{\partial v(f, t)}{\partial F_{t}} \\
& +\frac{1}{2} \cdot F_{t}^{2} \cdot \pi_{t}^{2} \cdot \sigma^{2} \cdot \frac{\partial^{2} v(f, t)}{\partial F_{t}^{2}}
\end{aligned}
$$

And with the terminal condition:

$$
v(f, T)=u_{2} \cdot \frac{f^{\gamma_{2}}}{\gamma_{2}}
$$

The classical method used to solve the HJB equation consists of proposing a form for the value function and next to inject it into the SDE (7) to reduce it to one or two ODE. The belonging of the optimal controls to the set of admissible solutions is generally checked a posteriori. This approach doesn't lead to an analytic solution for the problem treated in this paper.

\section{THE NUMERICAL METHOD}

\subsection{The Markov chains approximation}

As the problem of the individual's asset allocation doesn't accept any analytical solution, we have opted for a numerical approach, namely the Markov chain 
approximation by Kushner and Dupuis (2001). The first step consists in delimiting and fractioning a domain of resolution:

$$
\mathbb{D}=\left\{(t, f): t \in(0, \Delta t, \ldots, T) f \in\left(f_{l b}, f_{l b}+\Delta f, \ldots, f_{u b}\right)\right\}
$$

The choice of $f_{l b}$ and $f_{u b}$ and the method of discretization at those bounds are related to paragraphs 3.2 and 3.3. Developments achieved in this paragraph concern interior points of $\mathbb{D}$. The HJB equation (7) is discretized by replacing the partial derivatives by their finite difference equivalents.

$$
\begin{aligned}
0 & =v_{t}(f, t)-(\rho+\mu(x+t)) \cdot v(f, t)+\sup _{c_{t}, \pi_{t} \in \mathbb{U}}\left(\left(\left(r+\pi_{t} \cdot(m-r)\right) \cdot f+B_{x}\right) \cdot v_{F}^{+}(f, t)\right. \\
& \left.-c_{t} \cdot v_{F}^{-}(f, t)+1 / 2 \cdot \pi_{t}^{2} \cdot f^{2} \cdot \sigma^{2} \cdot v_{F F}(f, t)+U_{1}\left(c_{t}\right)+\mu(x+t) \cdot U_{2}(f)\right)
\end{aligned}
$$

With

$$
\begin{gathered}
v_{t}(f, t)=\frac{v(f, t+\Delta t)-v(f, t)}{\Delta t} \\
v_{F}^{+}(f, t)=\theta \cdot \frac{v(f+\Delta f, t)-v(f, t)}{\Delta f}+(1-\theta) \cdot \frac{v(f+\Delta f, t+\Delta t)-v(f, t+\Delta t)}{\Delta f} \\
v_{F}^{-}(f, t)=\theta \cdot \frac{v(f, t)-v(f-\Delta f, t)}{\Delta f}+(1-\theta) \cdot \frac{v(f, t+\Delta t)-v(f-\Delta f, t+\Delta t)}{\Delta f} \\
v_{F F}(f, t)=\theta \cdot \frac{v(f+\Delta f, t)+v(f-\Delta f, t)-2 \cdot v(f, t)}{\Delta f^{2}}+ \\
(1-\theta) \cdot \frac{v(f+\Delta f, t+\Delta t)+v(f-\Delta f, t+\Delta t)-2 \cdot v(f, t+\Delta t)}{\Delta f^{2}}
\end{gathered}
$$

Please note that the finite difference approximations $v_{F}^{+}$and $v_{F}^{-}$are respectively chosen for positive and negative coefficients of $\frac{\partial v(f, t)}{\partial F_{t}}$. This approach is known as the "upwind approximation method" in numerical analysis and it is necessary to have an interpretation of the discretized HJB equation (9) in terms of a Markov chain. The interested reader may refer to Kushner and Dupuis (2001), chapter 5, section 1 for illustrations of this point. $\theta$ is a parameter of overrelaxation. As the finite difference equivalents of the derivatives depend on $v(., t)$ and $v(., t+\Delta t)$, the algorithm developed in subsection 3.4, is implicit and iterative. The optimal consumption and investment policies are respectively noted $c_{t}^{*}$ and $\pi_{t}^{*}$. In order to simplify further calculations, the following notations are adopted:

$$
\begin{gathered}
b^{+}=\left(\left(r+\pi_{t}^{*} \cdot(m-r)\right) \cdot f+B_{x}\right) \\
b^{-}=c_{t}^{*} \\
a=\pi_{t}^{* 2} \cdot f^{2} \cdot \sigma^{2}
\end{gathered}
$$


Combining equations (9) to (16), and regrouping terms, allow us to rewrite (9) as:

$$
\begin{aligned}
& v(f, t) \cdot(1+(\rho+\mu(x+t)) \cdot \Delta \tilde{t})= \\
& \quad \sum_{\substack{i=0,1 \\
j=-1,0,1}} p\left(t+i \cdot \Delta t, f+j \cdot \Delta f \mid \pi_{t}^{*}, c_{t}^{*}\right) \cdot v(f+j \cdot \Delta f, t+i \cdot \Delta t) \\
& \quad+\left(U_{1}\left(c_{t}^{*}\right)+\mu(x+t) \cdot U_{2}(f)\right) \cdot \Delta \tilde{t}
\end{aligned}
$$

Where

$$
\begin{aligned}
& p\left(t, f \mid \pi_{t}^{*}, c_{t}^{*}\right)=0 \\
& p\left(t, f+\Delta f \mid \pi_{t}^{*}, c_{t}^{*}\right)=\frac{b^{+} \cdot \theta \cdot \frac{\Delta t}{\Delta f}+\frac{1}{2} \cdot a \cdot \theta \cdot \frac{\Delta t}{\Delta f^{2}}}{\left(1+b^{+} \cdot \theta \cdot \frac{\Delta t}{\Delta f}+b^{-} \cdot \theta \cdot \frac{\Delta t}{\Delta f}+a \cdot \theta \cdot \frac{\Delta t}{\Delta f^{2}}\right)} \\
& p\left(t, f-\Delta f \mid \pi_{t}^{*}, c_{t}^{*}\right)=\frac{b^{-} \cdot \theta \cdot \frac{\Delta t}{\Delta f}+\frac{1}{2} \cdot a \cdot \theta \cdot \frac{\Delta t}{\Delta f^{2}}}{\left(1+b^{+} \cdot \theta \cdot \frac{\Delta t}{\Delta f}+b^{-} \cdot \theta \cdot \frac{\Delta t}{\Delta f}+a \cdot \theta \cdot \frac{\Delta t}{\Delta f^{2}}\right)} \\
& p\left(t+\Delta t, f \mid \pi_{t}^{*}, c_{t}^{*}\right)=\frac{1-\left(b^{-}+b^{+}\right) \cdot(1-\theta) \cdot \frac{\Delta t}{\Delta f}-a \cdot(1-\theta) \cdot \frac{\Delta t}{\Delta f^{2}}}{\left(1+b^{+} \cdot \theta \cdot \frac{\Delta t}{\Delta f}+b^{-} \cdot \theta \cdot \frac{\Delta t}{\Delta f}+a \cdot \theta \cdot \frac{\Delta t}{\Delta f^{2}}\right)} \\
& p\left(t+\Delta t, f+\Delta f \mid \pi_{t}^{*}, c_{t}^{*}\right)=\frac{b^{+} \cdot(1-\theta) \cdot \frac{\Delta t}{\Delta f}+\frac{1}{2} \cdot a \cdot(1-\theta) \cdot \frac{\Delta t}{\Delta f^{2}}}{\left(1+b^{+} \cdot \theta \cdot \frac{\Delta t}{\Delta f}+b^{-} \cdot \theta \cdot \frac{\Delta t}{\Delta f}+a \cdot \theta \cdot \frac{\Delta t}{\Delta f^{2}}\right)} \\
& p\left(t+\Delta t, f-\Delta f \mid \pi_{t}^{*}, c_{t}^{*}\right)=\frac{b^{-} \cdot(1-\theta) \cdot \frac{\Delta t}{\Delta f}+\frac{1}{2} \cdot a \cdot(1-\theta) \cdot \frac{\Delta t}{\Delta f^{2}}}{\left(1+b^{+} \cdot \theta \cdot \frac{\Delta t}{\Delta f}+b^{-} \cdot \theta \cdot \frac{\Delta t}{\Delta f}+a \cdot \theta \cdot \frac{\Delta t}{\Delta f^{2}}\right)} \\
& \Delta \tilde{t}=\frac{\Delta t}{\left(1+b^{+} \cdot \theta \cdot \frac{\Delta t}{\Delta f}+b^{-} \cdot \theta \cdot \frac{\Delta t}{\Delta f}+a \cdot \theta \cdot \frac{\Delta t}{\Delta f^{2}}\right)}
\end{aligned}
$$

The parameters $\Delta f, \Delta t$ and $\theta$ are chosen such that all $p\left(., . \mid \pi_{t}^{*}, c_{t}^{*}\right)$ may be interpreted as probabilities of transition of a discrete random variable $Z \in\{v(t+$ $i . \Delta t, f+j . \Delta f) \forall i \in\{0,1\} \forall j \in\{-1,0,1\}\}$ :

$$
\begin{gathered}
\sum_{\substack{i=0,1 \\
j=-1,0,1}} p\left(t+i \cdot \Delta t, f+j . \Delta f \mid \pi_{t}^{*}, c_{t}^{*}\right)=1 \\
p\left(t+i . \Delta t, f+j . \Delta f \mid \pi_{t}^{*}, c_{t}^{*}\right) \geq 0 \quad \forall i \in\{0,1\} \forall j \in\{-1,0,1\}
\end{gathered}
$$


If (18) and (19) are verified at each point of the domain, the equation (17) may then be seen as a discrete version of the dynamic programming principle:

$$
Z \cdot(1+(\rho+\mu(x+t)) \cdot \Delta \tilde{t})=\mathbb{E}\left(Z \mid \pi_{t}^{*}, c_{t}^{*}\right)+\left(U_{1}\left(c_{t}^{*}\right)+\mu(x+t) \cdot U_{2}(f)\right) \cdot \Delta \tilde{t}
$$

If $\Delta \tilde{t}$ is sufficiently small,

$$
Z=e^{-(\rho+\mu(x+t)) \cdot \Delta \tilde{t}} \cdot \max _{c_{t}, \pi_{t} \in \mathbb{U}}\left(\mathbb{E}\left(Z \mid \pi_{t}, c_{t}\right)+\left(U_{1}\left(c_{t}\right)+\mu(x+t) \cdot U_{2}(f)\right) \cdot \Delta \tilde{t}\right)
$$

Equation (21) means that the current value of $Z$ is equal to the maximum, among all allowed controls, of the expected discounted value of $Z$, plus the gain of utility, realized during the small time interval $\Delta \tilde{t}$. In this framework, the convergence of the approximation of $v(f, t)$ when $\Delta \tilde{t} \rightarrow 0$, has been proved both by a viscosity approach (see Fleming and Soner, chapter 9, section 4) and by a probabilistic approach (see Dupuis and Kushner 2001, chapter 14, section 2). In numerical analysis, there isn't any rule to fix the value of $\theta$. However, we noticed that choosing a $\theta$ value close to one reduces the computation time and ensures that all $p\left(., . \mid \pi_{t}^{*}, c_{t}^{*}\right)$ are interpretable as probabilities of transition.

We end this paragraph by calculating optimal consumption and optimal investment policies. If we derive the discretized HJB equation with respect to $c_{t}$ and $\pi_{t}$, we obtain this:

$$
\begin{gathered}
c_{t}^{*}=\min \left(c_{b},\left(v_{F}^{-}(f, t)\right)^{\frac{1}{\gamma_{1}-1}}\right) \\
\pi_{t}^{*}=\min \left(\pi_{b},-\frac{m-r}{\sigma^{2}} \cdot \frac{1}{f} \cdot \frac{v_{F}^{+}(f, t)}{v_{F F}(f, t)}\right)
\end{gathered}
$$

$c_{b}$ is a bound on consumption related to the constraint on wealth $\left(F_{t} \geq 0\right)$. More details on $c_{b}$ are presented in the next subsection. The boundary on the investment policy $\pi_{t} \leq \pi_{b} \leq 100 \%$ is justified by the fact that the optimal strategy can be a short position in cash and a long one in equities. This kind of speculative portfolio cannot be carried out by an individual saver.

\subsection{Constraint on wealth and domain}

In the continuous formulation (7), the set of admissible controls, $\mathbb{U}$, is such that wealth remains positive and that a fraction of risky assets in portfolio is limited to a certain amount.

$$
\mathbb{U}=\left\{c_{t}, \pi_{t}: F_{t} \geq 0 \quad \pi_{t} \leq \pi_{b} \forall t \in[0, \tau]\right\}
$$


Constraint on wealth is inserted in the algorithm as a constraint on consumption. During the small step of time $\Delta t$, consumption may not exceed the sum of the fund market value and of the annuity paid in during this period:

$$
c_{t} \leq c_{b}=\frac{F_{t}}{\Delta t}+B_{x}
$$

In view of the previous expression, the bounds $f_{l b}$ of domain of resolution $\mathbb{D}$ defined by (8), is therefore equal to:

$$
f_{l b}=-B_{x} \cdot \Delta t
$$

The upper bound, $f_{u b}$ is chosen in function of the desired range of results.

\subsection{Approximations at the boundary}

We briefly describe the approximations adopted on the boundary of $\mathbb{D}$, and more precisely when $f \in\left\{f_{l b}, f_{u b}\right\}$.

When the wealth reaches the upper bound $f_{u b}$, the probabilities of remaining in the state $\left(f_{u b}, t\right)$ and the transition probabilities toward $\left(f_{u b}, t+\Delta t\right)$ are modified in order to take into account that the states $\left(f_{u b}+\Delta f,.\right)$ aren't defined:

$$
\begin{aligned}
p\left(t, f_{u b} \mid \pi_{t}^{*}, c_{t}^{*}\right) & =1-p\left(t, f_{u b}-\Delta f \mid \pi_{t}^{*}, c_{t}^{*}\right) \\
p\left(t+\Delta t, f_{u b} \mid \pi_{t}^{*}, c_{t}^{*}\right) & =1-p\left(t+\Delta t, f_{u b}-\Delta f \mid \pi_{t}^{*}, c_{t}^{*}\right)
\end{aligned}
$$

Whereas missing approximated derivatives are replaced by:

$$
\begin{gathered}
v_{F}^{+}\left(f_{u b}, t\right)=v_{F}^{+}\left(f_{u b}-\Delta f, t\right) \\
v_{F F}\left(f_{u b}, t\right)=v_{F F}\left(f_{u b}-\Delta f, t\right)
\end{gathered}
$$

Similarly, when wealth attains the lower bound $f_{l b}$, probabilities of remaining in the state $\left(f_{l b}, t\right)$ and the transition probabilities toward $\left(f_{l b}, t+\Delta t\right)$ are:

$$
\begin{aligned}
p\left(t, f_{l b} \mid \pi_{t}^{*}, c_{t}^{*}\right) & =1-p\left(t, f_{l b}+\Delta f \mid \pi_{t}^{*}, c_{t}^{*}\right) \\
p\left(t+\Delta t, f_{l b} \mid \pi_{t}^{*}, c_{t}^{*}\right) & =1-p\left(t+\Delta t, f_{l b}+\Delta f \mid \pi_{t}^{*}, c_{t}^{*}\right)
\end{aligned}
$$

Missing derivatives are replaced by:

$$
\begin{gathered}
v_{F}^{-}\left(f_{l b}, t\right)=v_{F}^{-}\left(f_{l b}+\Delta f, t\right) \\
v_{F F}\left(f_{l b}, t\right)=v_{F F}\left(f_{l b}+\Delta f, t\right)
\end{gathered}
$$




\subsection{Approximation in value space}

This paragraph presents the recursive approach used to compute the value function at each point of the domain $\mathbb{D}$. First, we introduce some matrix notations. Let $V(t)$ be the vector of $v\left(f_{j}, t\right)$ and $U\left(c_{t}, t\right)$ be the vector of utility gains $\left(U_{1}\left(c_{t}\right)+\mu(x+t) \cdot U_{2}\left(f_{j}\right)\right) \cdot \Delta \tilde{t}$, with $f_{j} \in\left\{f_{l b}, f_{l b}+\Delta f, \ldots, f_{u b}\right\}$. Tridiagonal matrices $M\left(c_{t}, \pi_{t}\right)$ and $P\left(c_{t}, \pi_{t}\right)$ contain respectively the factors multiplying $V(t)$ and $V(t+\Delta t)$ in the expression (17). The dynamic programming equation (17) becomes therefore:

$$
M\left(c_{t}^{*}, \pi_{t}^{*}\right) . V(t)=P\left(c_{t}^{*}, \pi_{t}^{*}\right) . V(t+\Delta t)+U\left(c_{t}^{*}, t\right) \forall t \in\{0, \Delta t, \ldots, T-\Delta t\}
$$

At time $t=T$, the value function is equal to the utility of a bequest.

$$
V(T)=u_{2} \cdot \frac{\left(f_{j}\right)^{\gamma_{2}}}{\gamma_{2}} \forall f_{j} \in\left\{f_{l b}, f_{l b}+\Delta f, \ldots, f_{u b}\right\}
$$

The algorithm of approximation in value space (also known as the method of successive approximations) performs backward iterations from $t=T-\Delta t$ to $t=0$, by step of time $-\Delta t$. The optimal consumption and investment policies $\left(c_{t}^{*}, \pi_{t}^{*}\right)$, are calculated by formulae (22) and (23). Matrices $M\left(c_{t}^{*}, \pi_{t}^{*}\right)$ and $P\left(c_{t}^{*}\right.$, $\left.\pi_{t}^{*}\right)$ are then computed and the vector of value function $V(t)$ is obtained by the resolution of the linear system of equations (25). This system is easily solved by Gaussian elimination. As the finite difference method for approximating the derivatives of $v(f, t)$ is implicit, the backward iterations from $T-\Delta t$ to 0 are repeated till convergence. The accuracy $\omega_{f, t}$ at each point $(f, t) \in \mathbb{D}$ is next estimated by the HJB equation:

$$
\begin{gathered}
\omega_{f, t}=v_{t}(f, t)-(\rho+\mu(x+t)) \cdot v(f, t)+\left(\left(r+\pi_{t}^{*} \cdot(m-r)\right) \cdot f+B_{x}\right) \cdot v_{F}^{+}(f, t) \\
-c_{t}^{*} \cdot v_{F}^{-}(f, t)+1 / 2 \cdot \pi_{t}^{* 2} \cdot f^{2} \cdot \sigma^{2} \cdot v_{F F}(f, t)+U_{1}\left(c_{t}^{*}\right)+\mu(x+t) \cdot U_{2}(f)
\end{gathered}
$$

The quality of the approximated solution is measured by the matrix norm of errors:

$$
\omega=\sqrt{\sum_{f, t \in \mathbb{D}} \omega_{f, t}^{2} / n_{\mathbb{D}}}
$$

Where $n_{\mathbb{D}}$ is the number of mesh points of $\mathbb{D}$.

\section{Optimal choice without a BeQuest motive}

In this section, the situation of a pensioner without a bequest motive $\left(u_{2}=0\right)$ is analysed and some general conclusions are drawn from numerical results. 
In the next subsection, the optimal pattern of consumption and the evolution of the fund managed by the individual, are developed for three scenarios, when $70 \%$ of the initial wealth $\left(W_{0}=100\right)$ is devoted to the purchase of an annuity. In paragraph 4.2, the same exercise is done for a full annuitization. The section is then finished by the valuation of the optimal allocation of the initial wealth between an annuity and a self managed fund.

\subsection{Partial annuitization}

We consider a 60 year old pensioner, who decides to invest $70 \%$ of his capital in a life annuity, providing a continuous income of $B_{60}=4.68$. The risk free rate, the average return and volatility of stocks worth respectively $r=3.25 \%$, $m=6.00 \%$ and $\sigma=30.0 \%$. The mortality rates (real and those of the tariff) are given by a Gompertz-Makeham distribution (see appendix for details). There is no commercial loading $\varepsilon=0$. The risk aversion parameter related to consumption, $\gamma_{1}$, is set to 0.60 and the psychological discount factor, $\rho$, is assumed equal to $2 \%$. The discretization parameters used here and in the sequel of this paper are $\Delta t=0.5, \Delta f=0.1$ and $\theta=0.95$ (those values leads to errors $\omega$ smaller than 0.015).

Three scenarios, in which the return on assets is constant, are studied. Those scenarios are chosen in order to reflect a poor, an average and a good performance of investments. The variation of the fund $F_{t}$ during the interval of time $\Delta t$ obeys to the following equation:

$$
\Delta F_{t}=\left(r_{\text {scenario }} \cdot F_{t}-c_{t}+B_{x}\right) . \Delta t
$$

Where $r_{\text {scenario }}$ takes respectively the values $0.75 \%, 3.25 \%$ or $5.25 \%$. The last scenario considered is a genuine sample path.

Figures 1 and 2 respectively depict the consumption and the evolution of the fund. In each scenario, it clearly emerges that the pensioner will deplete his savings before the age of 83 years. Beyond this age, the individual consumes the pension $B_{x=60}$, in its totality. In a market with only one risk free rate asset, similar patterns of consumption were already established in a previous paper (Devolder and Hainaut 2005), with a method combining Lagrangian multipliers and the HJB equation.

In this example, the optimal investment policy consists in investing the whole wealth in the risky asset, $\pi_{t}=100 \%$, which is the chosen upper bound on $\pi_{t}$. Relaxing this bound leads to an optimal solution with a huge long position in equities and a short position in cash. In this situation, it seems that the optimal proportion of stocks is partially proportional to the sum of the market value of the fund and of the mathematical reserve. But as mentioned previously, this solution is quite unrealistic and for this reason, we didn't develop it. 


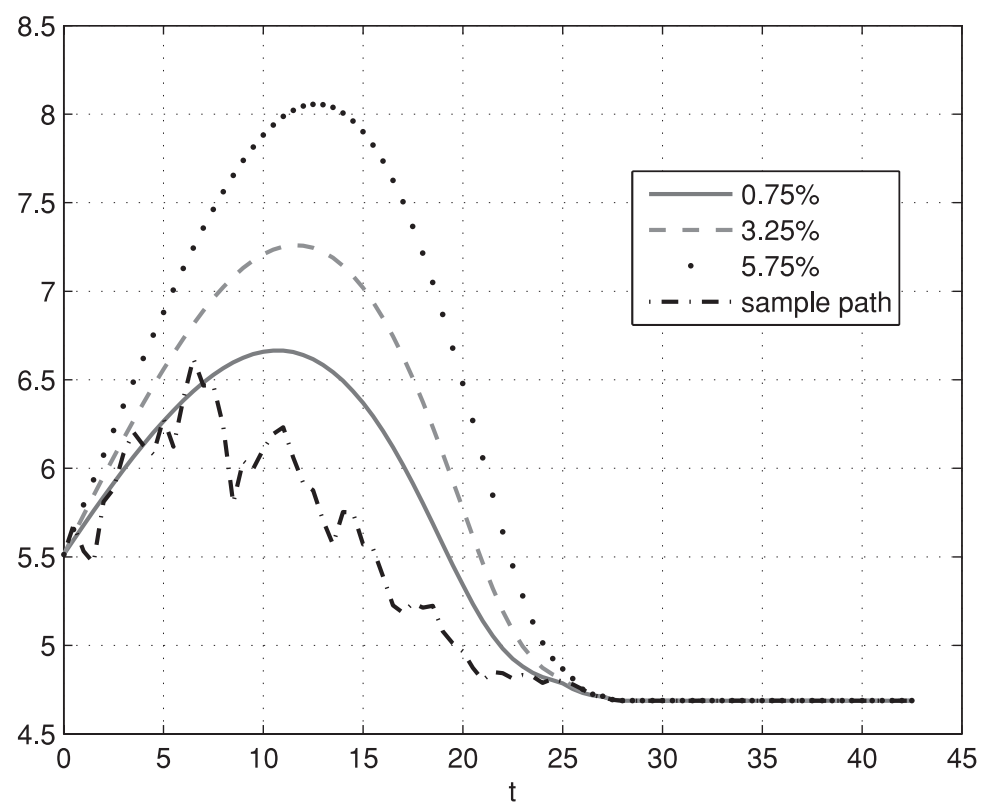

FIGURE 1. Consumption evolution, $\alpha=70 \%$.

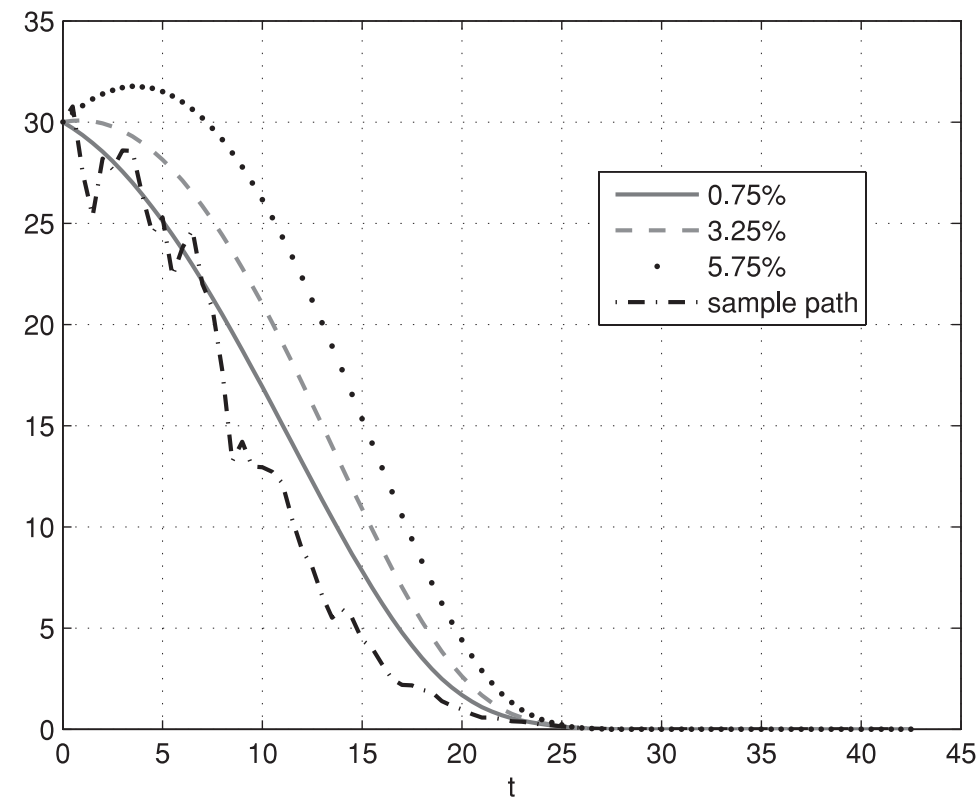

Figure 2. Fund evolution, $\alpha=70 \%$. 


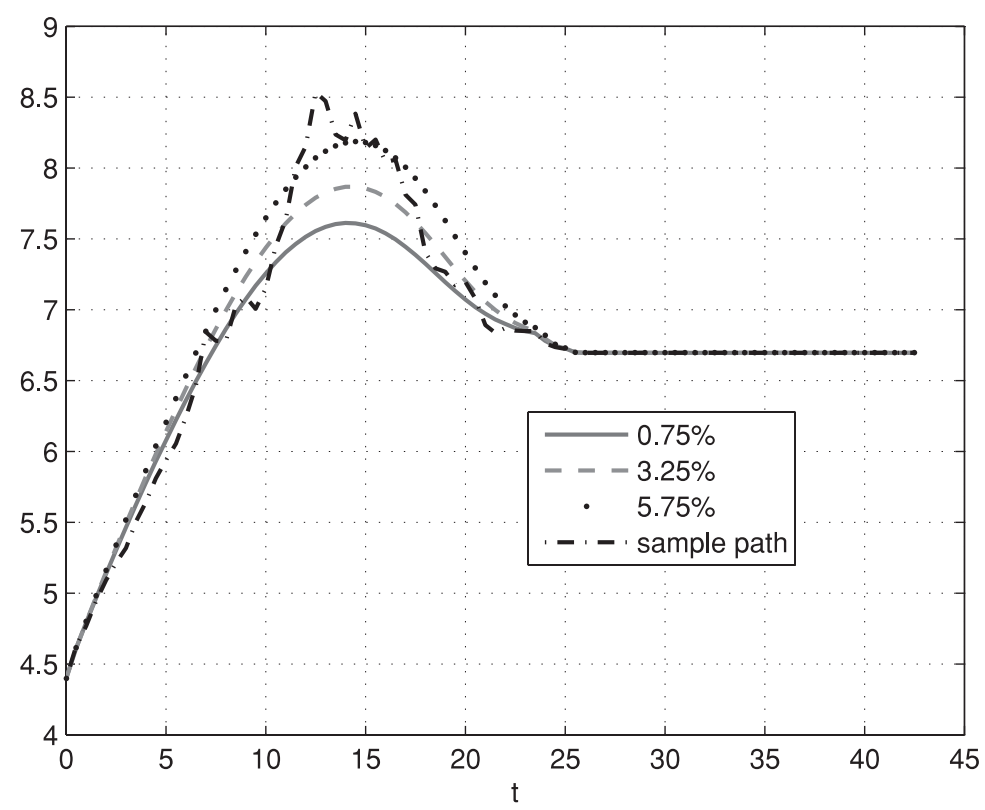

Figure 3. Evolution of the consumption, $\alpha=100 \%$.

\subsection{Full annuitization}

Under the same assumptions as observed previously, the optimal pattern of consumption/investment is computed when the retiree decides to invest $100 \%$ of his initial wealth in a life annuity, with a rate $B_{x=60}$ of 6.70 .

The optimal pattern of consumption (figure 3 ) is brokedown into three periods. The first one, extending from age 60 to 68 , is a phase of capitalization. A major part of the annuity is consumed whereas the residue is totally invested in the risky asset. During the second period, from 68 to 83 years of age, the individual consumes more than the annuity and depletes the fund. Finally, in the third period, the consumption is equal to the annuity. The existence of the first phase of capitalization clearly reveals that in a market including a risky asset, the individual without any bequest motive would be better of investing part of his patrimony in it. The amount placed in the financial market, is quite evidently function of the retiree's risk appetite, $\gamma_{1}$ and of the psychological discount factor $\rho$. This observation motives developments explained in the next paragraph.

\subsection{The annuity puzzle}

We observed that in case of a full annuitization, part of the annuity is reinvested. It is therefore interesting to seek an optimal fraction $\alpha^{*}$ of the initial 


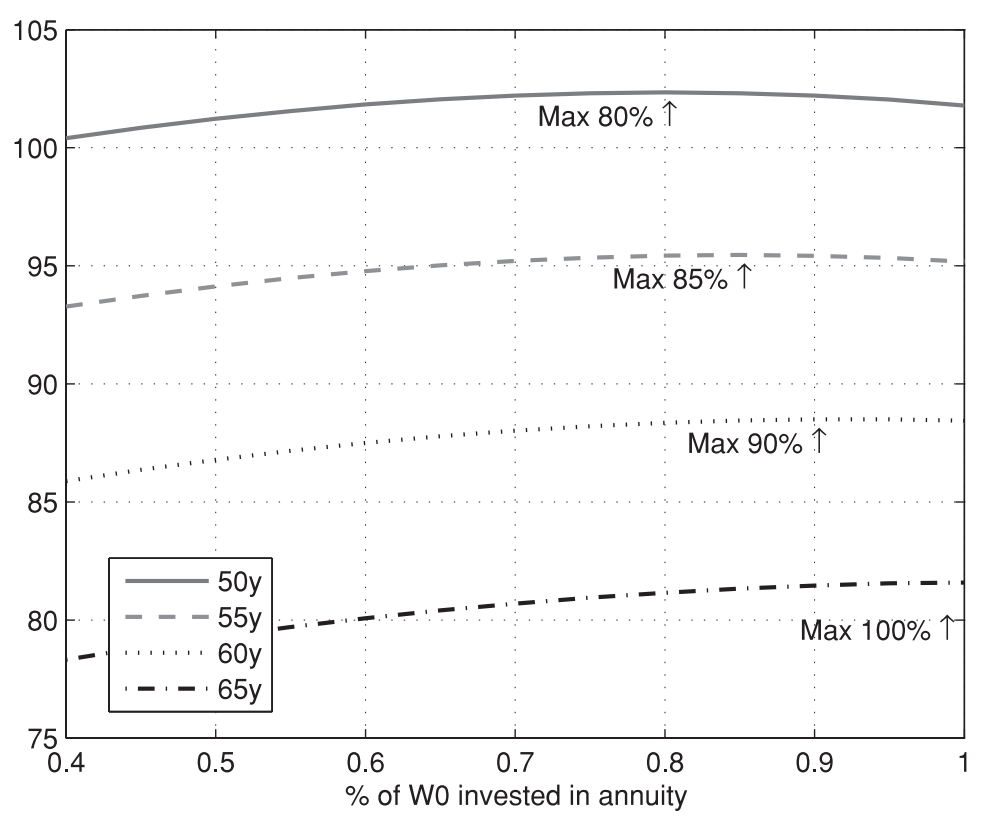

FIGURE 4. Value function by age and $\alpha$.

wealth that the pensioner should dedicate to the purchase of an annuity, in order to maximize the discounted value of the expected utility arising from consumption.

$$
\alpha^{*}=\arg \sup _{\alpha} v\left((1-\alpha) \cdot W_{0}, 0\right)
$$

A first answer is delivered by the graph 4 which presents the value function for different levels $\alpha$ of annuitization, and for different ages of annuity purchase. All other assumptions (volatility, mortality, ...) are identical to those used in previous examples. We observe that, even if the curvature is not important, a peak emerges at each age of purchase. This peak goes from $\alpha^{*}=80 \%$ when the agent is 50 years old, to $\alpha^{*}=100 \%$ at 65 years old. This is an interesting observation: a young retired individual, without a bequest motive, should not neglect the opportunities of the financial market. We mitigate the results of Yaari in the sense that a small diversification between market risk and mortality risk is the optimal personal strategy of investment.

The cost of choosing a suboptimal strategy is illustrated by table 1 which contains the percentage $\beta$ of initial capital $W_{0}$ lost due to bad asset allocation. $\beta$ is solution of the following equation:

$$
v\left((1-\alpha) \cdot W_{0}, 0\right)=v\left(\left(1-\alpha^{*}\right) \cdot(1-\beta) \cdot W_{0}, 0\right)
$$


The impact of a bad strategy choice is less important when the individual is young. Choosing to invest $40 \%$ instead of $80 \%$ of the wealth in a life annuity costs $1.71 \%$ of $W_{0}$, at 50 years. Whereas investing $40 \%$ instead of $100 \%$ in a life annuity costs $3.57 \%$ of $W_{0}$ at 65 years.

TABLE 1

Costs OF SUBOPTIMAL STRATEGIES ( $\%$ OF $\left.W_{0}\right)$.

\begin{tabular}{c|c|c|c|c}
\hline \hline$\alpha$ & $50 \mathrm{y}$ & $55 \mathrm{y}$ & $60 \mathrm{y}$ & $65 \mathrm{y}$ \\
\hline $40 \%$ & 1.71 & 2.06 & 2.64 & 3.57 \\
$45 \%$ & 1.34 & 1.65 & 2.18 & 3.04 \\
$50 \%$ & 1.01 & 1.29 & 1.77 & 2.56 \\
$55 \%$ & 0.73 & 0.97 & 1.40 & 2.13 \\
$60 \%$ & 0.49 & 0.69 & 1.07 & 1.73 \\
$65 \%$ & 0.29 & 0.46 & 0.78 & 1.37 \\
$70 \%$ & 0.14 & 0.27 & 0.54 & 1.06 \\
$75 \%$ & 0.05 & 0.14 & 0.34 & 0.78 \\
$80 \%$ & 0.00 & 0.04 & 0.18 & 0.54 \\
$85 \%$ & 0.01 & 0.00 & 0.07 & 0.34 \\
$90 \%$ & 0.07 & 0.01 & 0.00 & 0.18 \\
$95 \%$ & 0.19 & 0.07 & 0.01 & 0.07 \\
$100 \%$ & 0.38 & 0.19 & 0.01 & 0.00 \\
\hline \hline
\end{tabular}

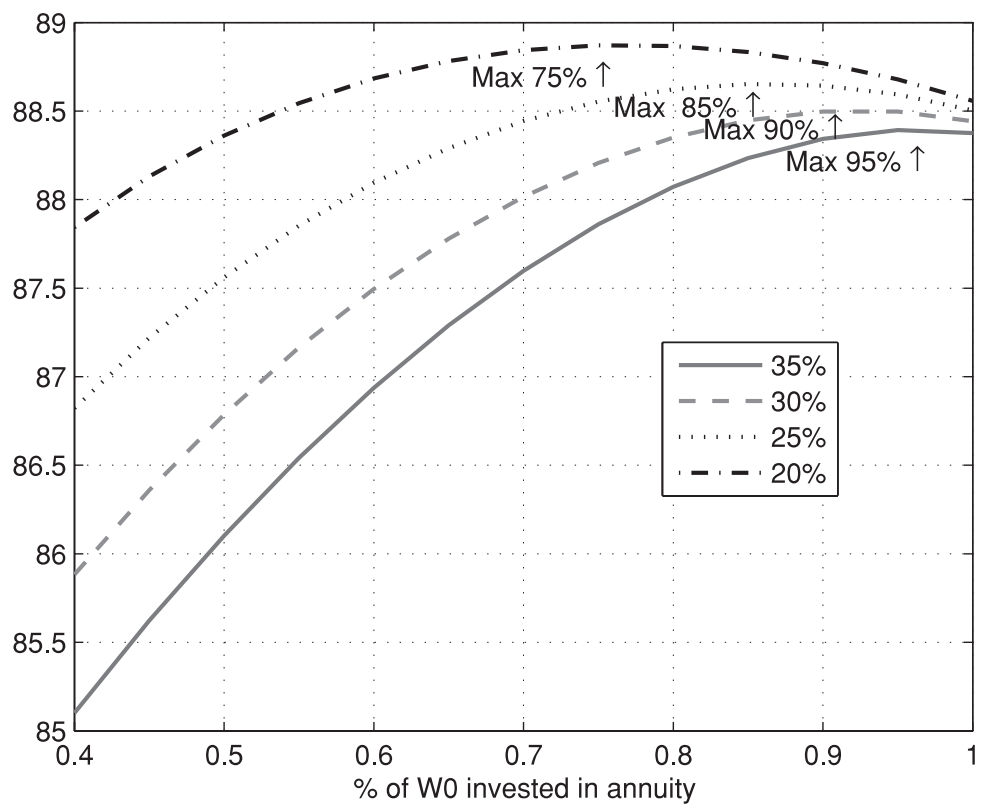

FIGURE 5. Value function by volatility and $\alpha$. 


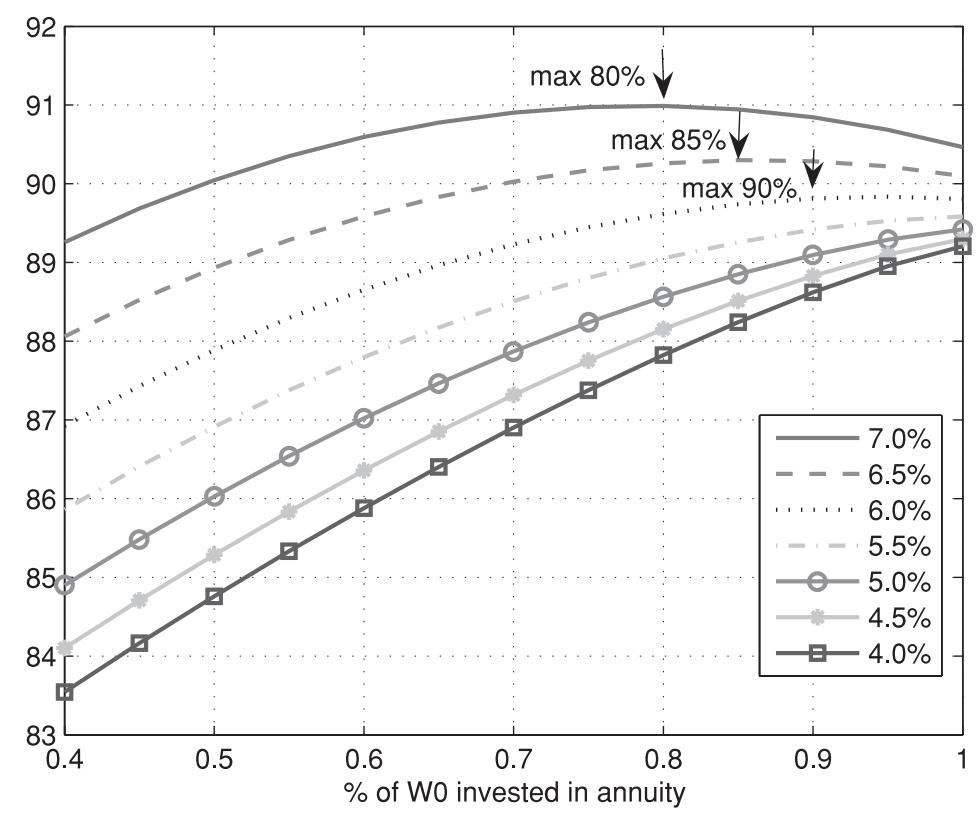

FIGURE 6. Value function by return of stocks $m$ and $\alpha$.

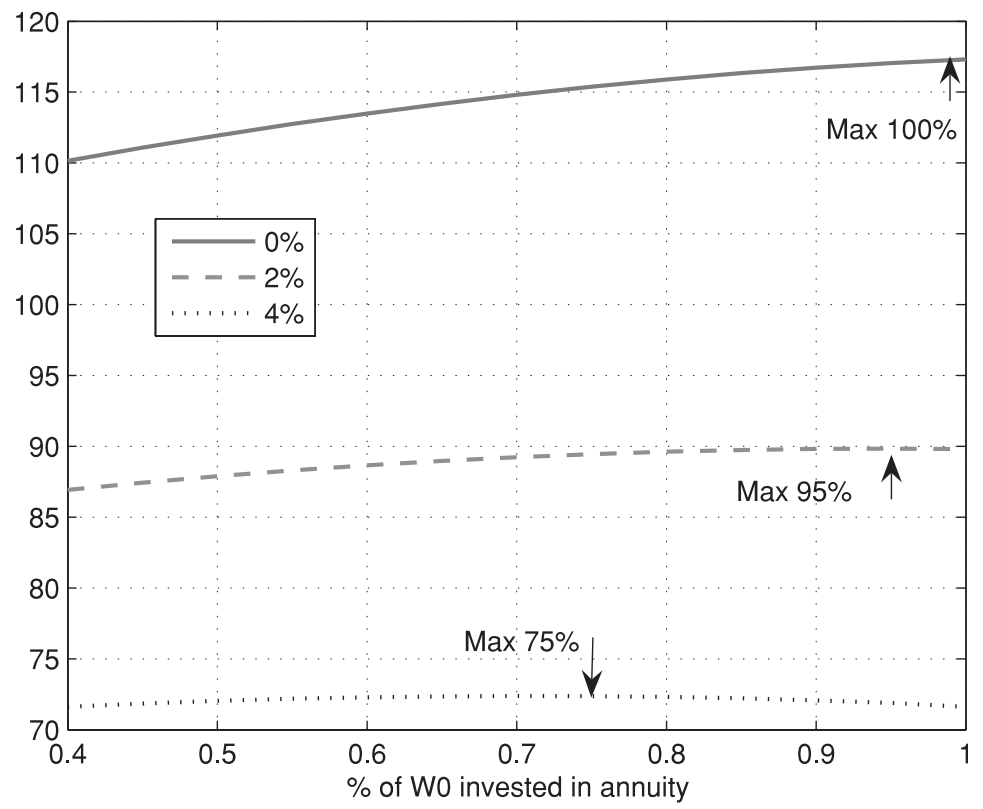

FIGURE 7. Value function by discount factor $\rho$ and $\alpha$. 
As showed in figure 5, the optimal asset allocation for a 60 year old individual, is however very sensitive to the volatility of the risky asset (when $m=6 \%$ ). Without any surprise, there is a negative correlation between the volatility of equities and the optimal fraction of capital dedicated to the self managed fund. When the volatility reaches $35 \%$, it is nearly not interesting to invest in the financial market.

The mean stocks return also widely influences the optimal level of annuitization. The figure 6 presents the impact of $m$ on the value function for a 60 year old retiree and a volatility $\sigma$ of $30 \%$. The higher the risk premium of risky assets, the smaller will be the fraction of the initial endowment devoted to purchase an annuity. For stocks return inferior to $5.5 \%$, the optimal allocation is a full annuitization.

We close this section by introducing the relation between psychological discount factor $\rho$ and optimal asset allocation (figure 7). Given that $\rho$ measures the pensioner's subjective rate of time preference, an individual with a small $\rho$ shouldn't hesitate deferring his consumption and to invest in a life annuity. On the contrary, a retiree having an big $\rho$ will prefer to consume at short term part of his capital and limit his position in annuity.

\section{Optimal Choice With A Bequest motive}

We now consider the case of an individual who wishes both to pass on a bequest $\left(u_{2}=1\right)$ to his relatives and to partly consume his capital. The chosen risk aversion parameters $\gamma_{1}, \gamma_{2}$ are: $\gamma_{1}=0.20, \gamma_{2}=0.60$. The first subsection introduces a pattern of consumption/investment in the case of partial annuitization. Next, the optimal allocation between annuity and fund is analysed for different ages, stocks volatilities, stocks returns, and different bequest motives.

\subsection{Partial annuitization}

Once more, analysis is done for a 60 year old pensioner who dedicates $70 \%$ of his wealth to purchase a life annuity, providing an income of $B_{x=60}=4.68$. Others parameters are identical to those used in previous examples. As in the previous section, four scenarios are developed. In the first three, the return on investment is constant $(0.75 \%, 3.25 \%$ and $5.75 \%)$ whereas the last scenario is a genuine sample path.

Figures 8 and 9 respectively depict the evolution of the optimal consumption and of the retiree's savings. For each scenario, consumption rate is inferior to the annuity during the first years. As one will remark on graph 10, the fraction of the annuity capitalized is totally invested in risky assets during this phase of accumulation. For the three first scenarios, after 4, 7 or 14 years, depending on the asset return, consumption may become higher than the annuity. However, when the financial return is high enough (scenario 5.75\%), the individual's 


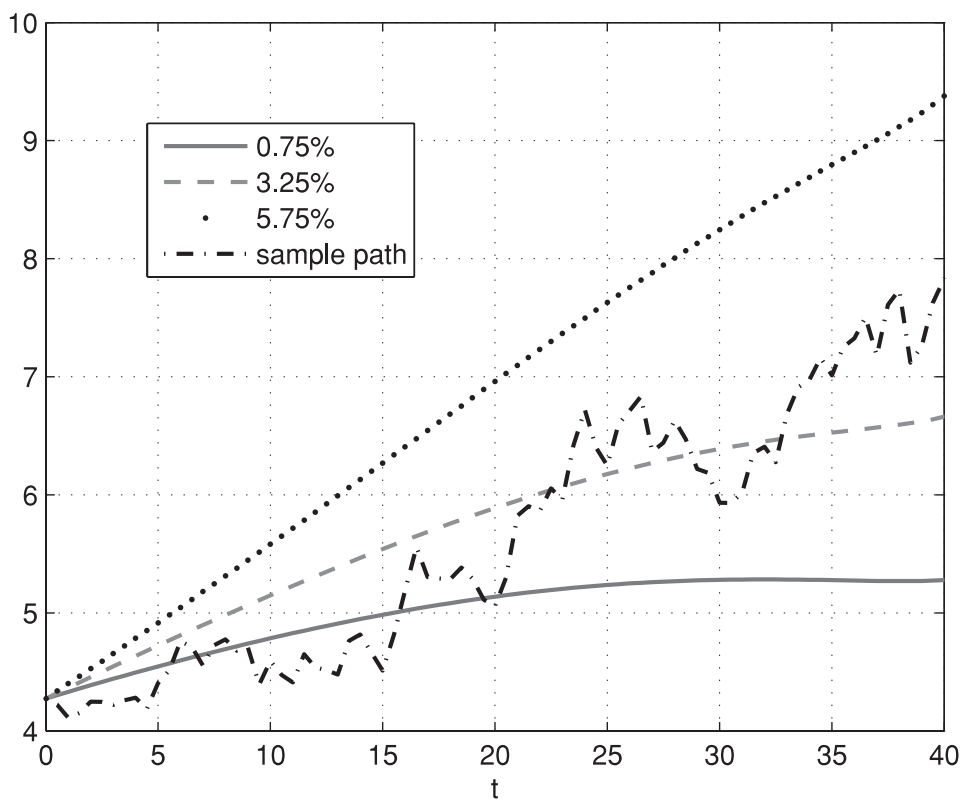

FIGURE 8. Consumption evolution.

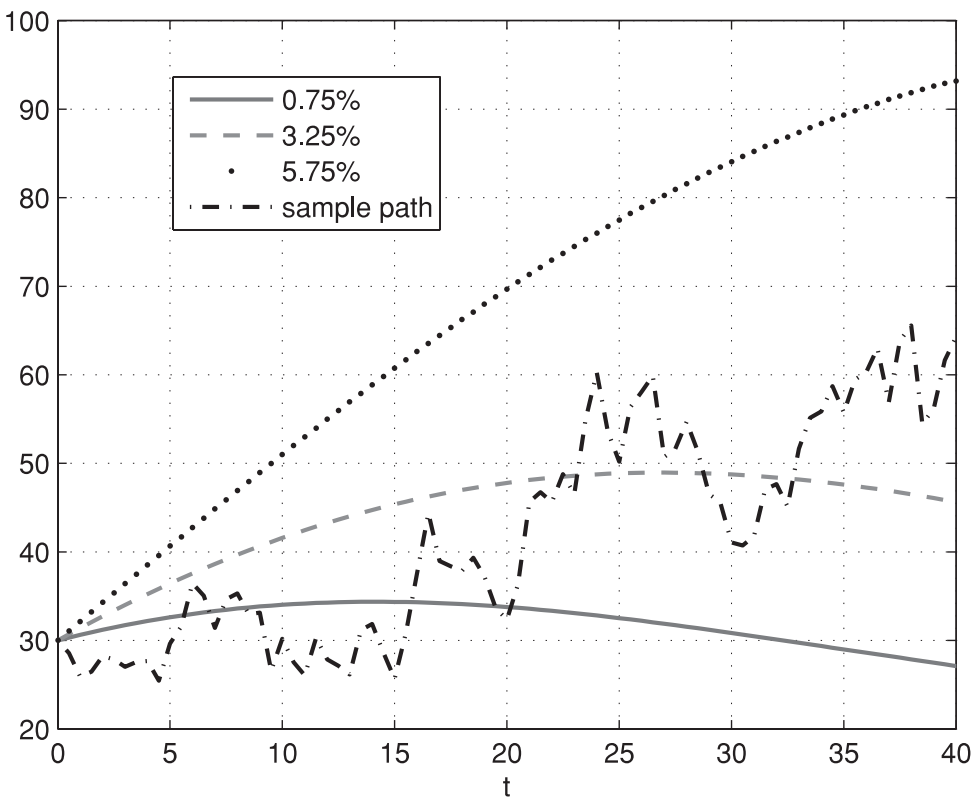

FIGURE 9. Fund evolution. 


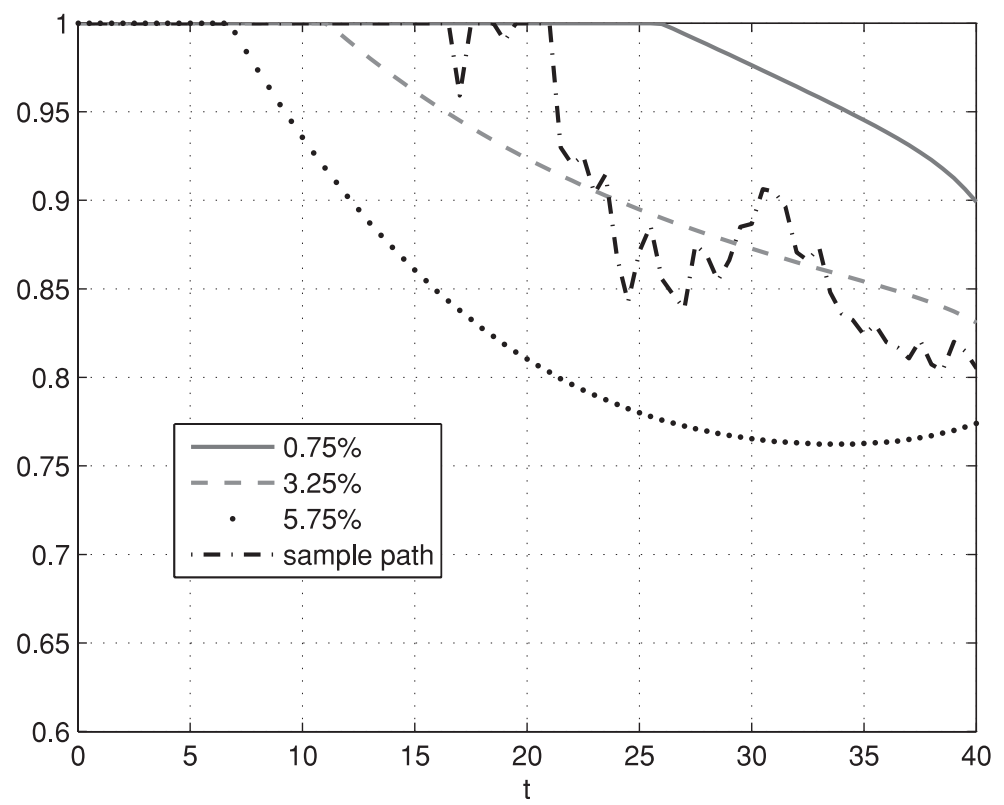

FIGURE 10. Investment policy.

fund doesn't decrease. In this case, the gap between consumption and annuity rates is financed by the assets financial performance.

We finalize this section with a comment about the evolution of investment policy, figure 10. As mentioned early, the totality of the fund is placed in risky assets, over the first years. We notice that quicker is the fund growth, quicker will be the decrease of equities position. When the fund performs well (scenario $5.75 \%$ ), the position of risky asset is reduced after 7 years. Whereas in case of poor performance (scenario $0.75 \%$ ), the part of risky asset is reduced only after 27 years. Such investment strategies are coherent with the well accepted principle that the equities position should always decrease with age.

\subsection{The annuity puzzle}

As in paragraph 4.3, we seek the optimal fraction $\alpha^{*}$ of the initial capital that should be devoted to the purchase of an annuity, in order to maximize the expected utility.

The graph 11, demonstrates the value function for different levels of annuitization and for different ages of annuity purchase. The set of assumptions are identical to the ones in the previous examples. The curvature of the value functions is not important but it is possible to draw a maximum at each age of purchase. For the chosen preference parameters $\left(\gamma_{1}=0.20, \gamma_{2}=0.60\right)$, the optimal level of annuitization, $75 \%$, is independent of the pensioner's age. 


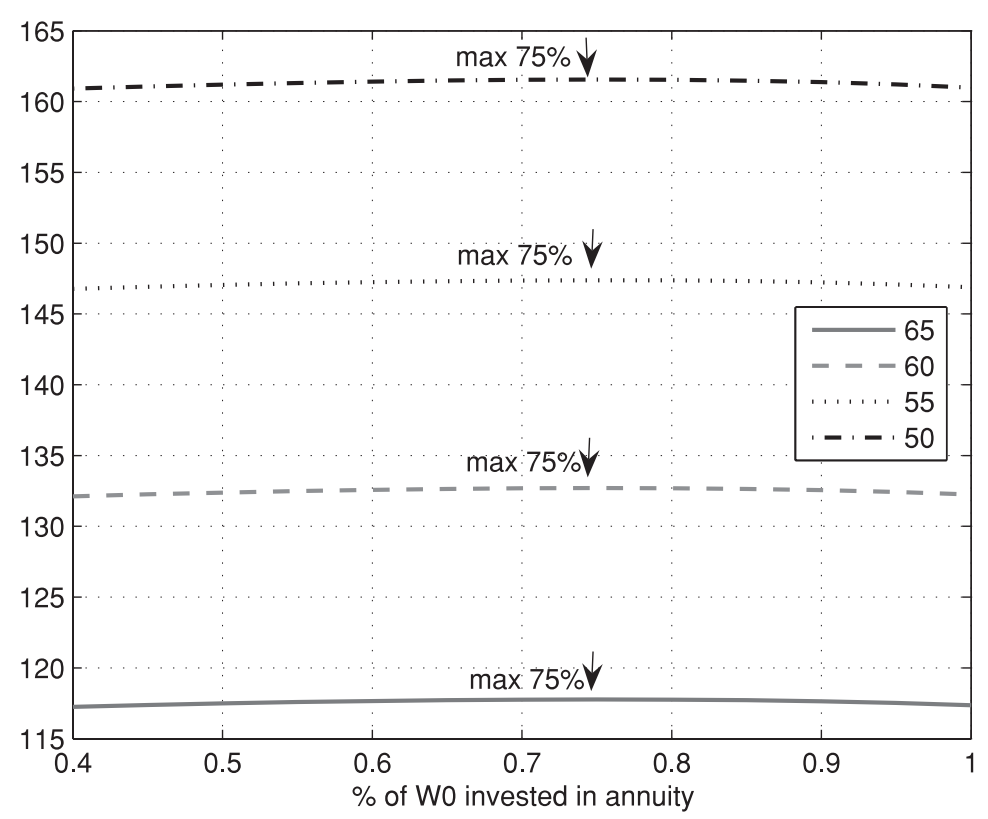

FIGURE 11. Value function by age and $\alpha$.

Table 2 presents the percentage $\beta$ of initial capital lost due to the choosing of a suboptimal investment strategy ( $\beta$ is defined by equation (28)). In this particular case, the cost of choosing a wrong level of annuitization is nearly independent of the individual's age. Investing $40 \%$ in a life annuity rather $75 \%$

TABLE 2

Costs of SUbOPTIMAL STRATEGIES ( $\%$ oF $\left.W_{0}\right)$.

\begin{tabular}{c|c|c|c|c}
\hline \hline$\alpha$ & $50 \mathrm{y}$ & $55 \mathrm{y}$ & $60 \mathrm{y}$ & $65 \mathrm{y}$ \\
\hline $40 \%$ & 1.81 & 1.86 & 1.89 & 1.87 \\
$45 \%$ & 1.38 & 1.41 & 1.44 & 1.42 \\
$50 \%$ & 0.99 & 1.03 & 1.05 & 1.02 \\
$55 \%$ & 0.67 & 0.69 & 0.70 & 0.67 \\
$60 \%$ & 0.40 & 0.41 & 0.42 & 0.39 \\
$65 \%$ & 0.19 & 0.21 & 0.21 & 0.18 \\
$70 \%$ & 0.06 & 0.06 & 0.06 & 0.05 \\
$75 \%$ & 0.00 & 0.00 & 0.00 & 0.00 \\
$80 \%$ & 0.05 & 0.04 & 0.04 & 0.04 \\
$85 \%$ & 0.20 & 0.19 & 0.19 & 0.19 \\
$90 \%$ & 0.50 & 0.48 & 0.46 & 0.47 \\
$95 \%$ & 0.96 & 0.90 & 0.88 & 0.88 \\
$100 \%$ & 1.61 & 1.53 & 1.47 & 1.46 \\
\hline \hline
\end{tabular}


involves a loss of approximatively $1.85 \%$ whatsoever the pensioner's age. Investing $100 \%$ in a life annuity leads to a loss between $1.46 \%$ and $1.61 \%$.

Figures 12 and 13 respectively show the influence of volatility (with $m=6 \%$ ) and of stocks average return (with $\sigma=30 \%$ ) on the optimal level of annuitization, for a 60 year old retired individual. There is a positive correlation between annuitized capital and volatility. If stocks volatility falls to $20 \%$ then $60 \%$ of the wealth should be annuitized. On the contrary, the annuitization level is negatively correlated to the mean stocks return. For an average return of $7 \%$, the amount annuitized decreases to $70 \%$. We also observe that, despite the bequest motive, the level of annuitization climbs to $95 \%$ if the average stocks return is only of $4 \%$.

The influence of the psychological discount factor $\rho$ on the optimal asset allocation (figure 14) is similar to the one observed for an individual without any bequest motive. An individual, who is not in a hurry to consume, defers his consumption and invests an important part of his wealth in a life annuity.

Finally, we analyze the influence of the bequest motive on the optimal asset allocation. For a given consumption utility, $\gamma_{1}=0.20$ and a given weight $u_{2}=1$, figure 15 depicts the impact of the bequest parameter, $\gamma_{2}$, on the value function, for a 60 year old retiree. In agreement with our intuition, the smaller the bequest motive, the higher must be the proportion of the initial wealth invested in a life annuity.

Figure 16 depicts the impact of the burden of bequest $u_{2}$, on the value function, for a 60 year old retiree with $\gamma_{1}=0.20$ and $\gamma_{2}=0.60$. According to

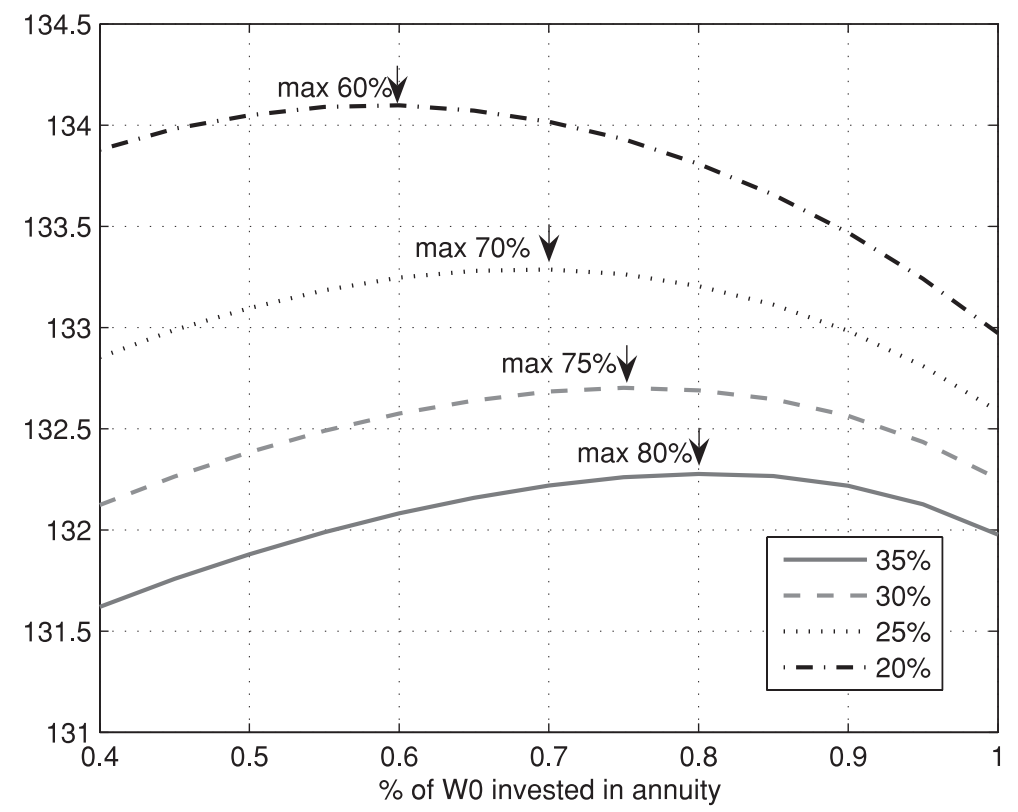

FIGURE 12. Value function by volatility and $\alpha$. 


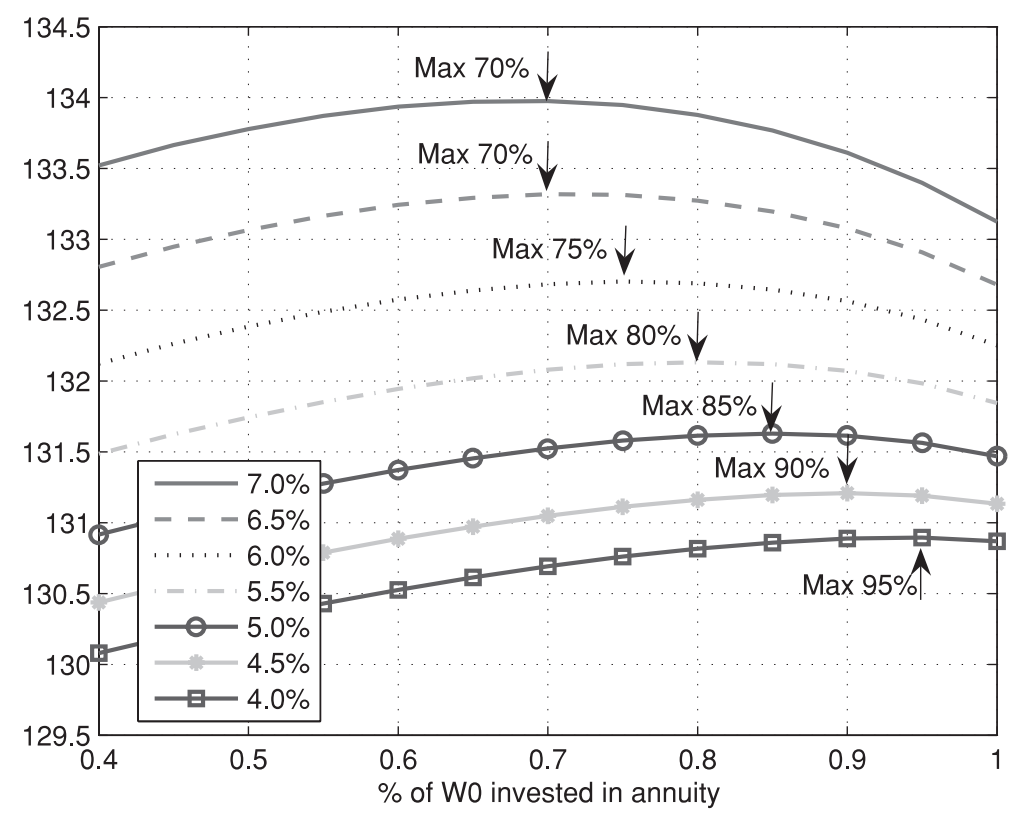

FigURE 13. Value function by return of stocks $m$ and $\alpha$.

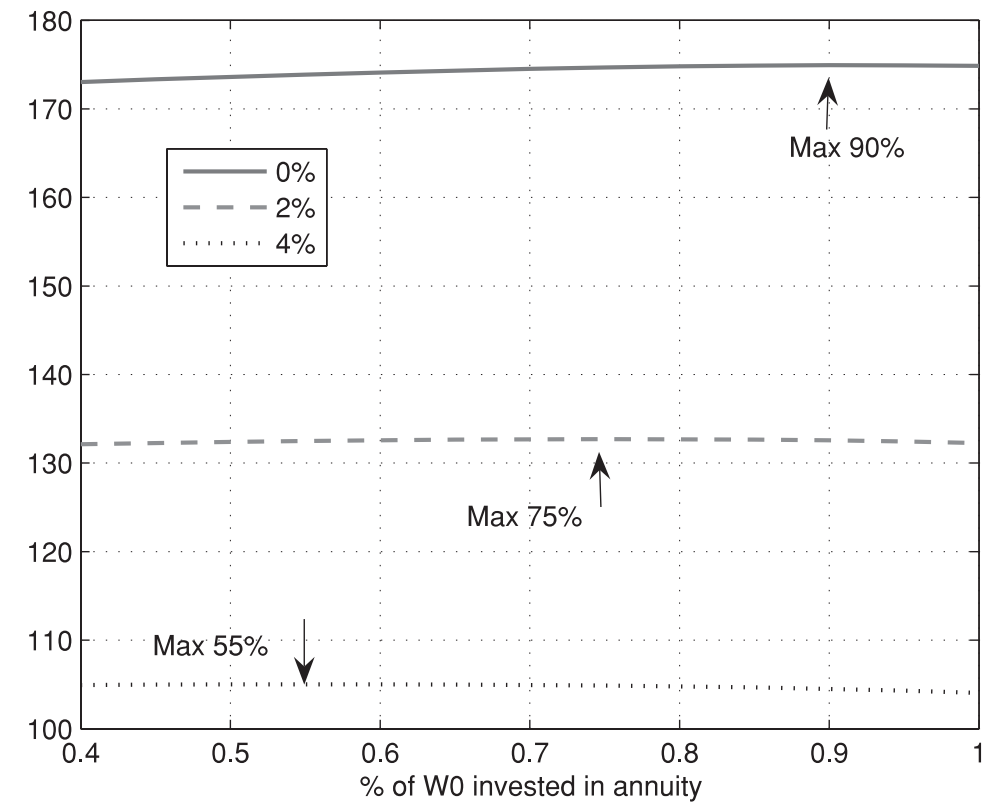

FiguRE 14. Value function by discount rate $\rho$ and $\alpha$. 


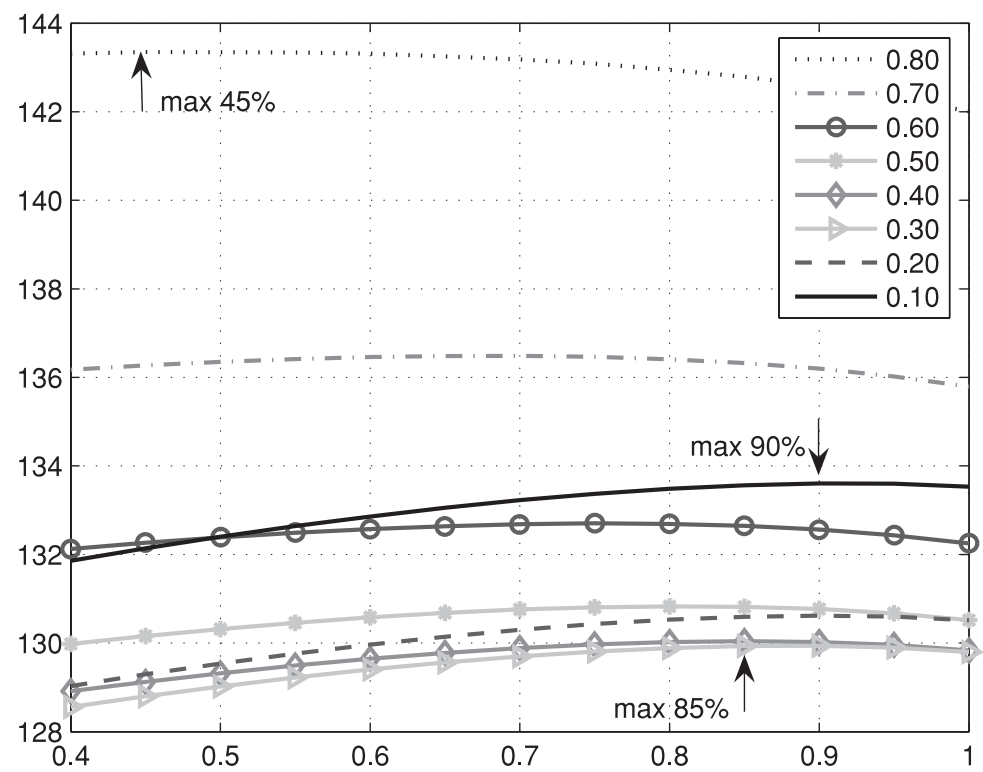

Figure 15. Value function by $\gamma_{2}$ and $\alpha$.

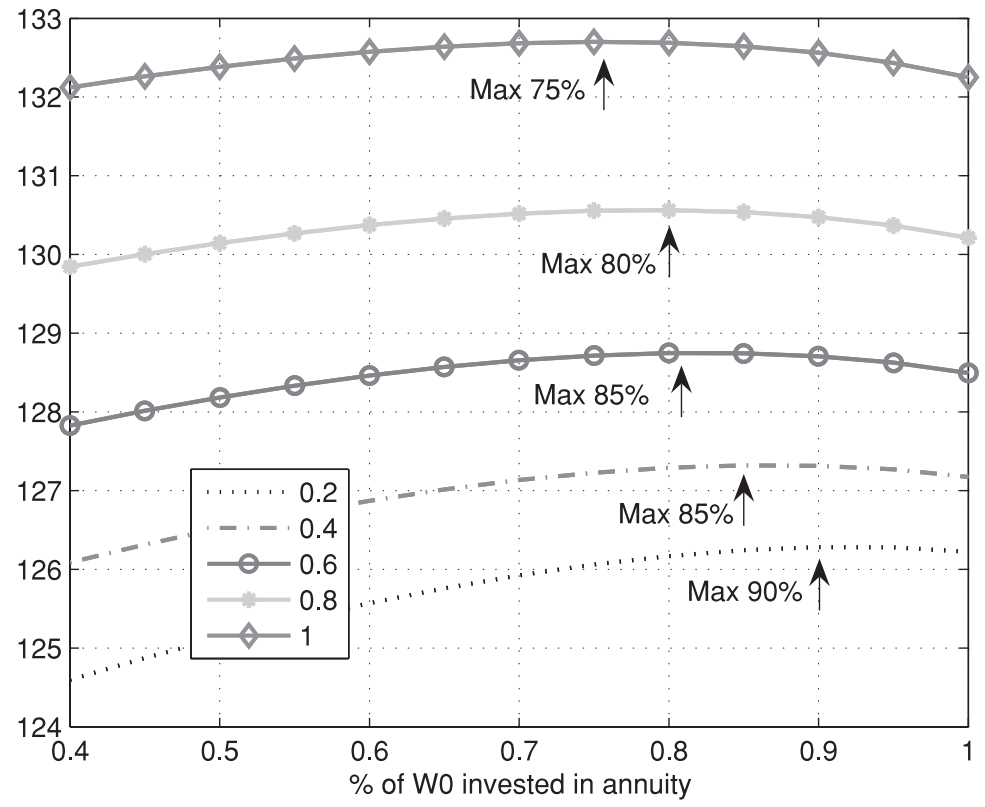

FIGURE 16. Value function by $u_{2}$ and $\alpha$. 
Blake et al. (1993) the value of $u_{2}$ reflects the family characteristics of the pensioner. A married man with children has a greater bequest motive and hence a higher value of $u_{2}$ than a single man. One may observe that the higher is $u_{2}$, the smaller is the proportion of the initial wealth invested in a life annuity.

\section{CONCLUSIONS}

This paper tries to solve the individual asset allocation problem for a pensioner who wants to maximize the expected utility of his future consumption, with or without a bequest motive. After a brief presentation of the market, one establishes the HJB equation coupled with this maximization problem. As an analytical solution is currently unavailable, we have opted for the numerical method developed by Kushner and Dupuis (2001), which mainly consists of the implicit discretization of partial derivatives included in the HJB equation. If parameters of discretization are well chosen, the HJB equation can be rewritten as a discrete dynamic programming equation and the convergence toward the unique viscosity solution is guaranteed.

An important part of this work is devoted to the analysis of examples from which we draw some general remarks. First of all, we address the case of an individual without any bequest motive. In such a situation, we observe that the pensioner should invest a fraction of his wealth in a life annuity. The annuitized amount is proportional to the pensioner's age and to the volatility of the risky asset and inversely proportional to the stocks return. The consumption pattern can also be decomposed in two periods: during the first one, the wealth constraint is inactive $\left(F_{t}>0\right)$ and the individual's savings decrease. In the second period, the constraint is active $\left(F_{t}=0\right)$ and the optimal consumption is equal to the annuity.

Finally, we show that, even with a bequest motive, the retiree should annuitize an important part of his patrimony to maximize his expected utility. Again, the capital dedicated to the purchase of equities is function of the pensioner's age, of the volatility and expected return of the risky asset. In many scenarios, the optimal consumption is lower than the annuity during the first years and savings increase (it's a capitalization phase). We also observe that the optimal part of the fund invested in the risky asset decreases with age.

In conclusion, this paper presents rational arguments in favour of the integration of an annuity in the individual asset allocation. Intuitively, our results may be explained by the fact that the mortality risk credit is in many cases more attractive than the risk premium of other risky assets.

\section{APPENDIX}

In the examples presented in this paper, we assume that the real mortality rates and the mortality rates used for pricing, $\mu(x+t)$ are given by a Gompertz-Makeham distribution. The parameters are those defined by the Belgian regulator 
for the pricing of a life insurance purchased by males. For an individual of age $\mathrm{x}$, the mortality rate is:

$$
\mu(x)=\mu^{t f}(x)=a_{\mu}+b_{\mu} \cdot c^{x} \quad a_{\mu}=-\ln \left(s_{\mu}\right) \quad b_{\mu}=\ln \left(g_{\mu}\right) \cdot \ln \left(c_{\mu}\right)
$$

Where the parameters $s_{\mu}, g_{\mu}, c_{\mu}$ take the values showed in the table 3. Table 4 presents the evolution of mortality rates according to the age of the individual.

TABLE 3

BELGIAN LEGAL MORTALITY, FOR LIFE INSURANCE PRODUCTS, AND FOR A MALE POPULATION.

\begin{tabular}{l|l}
\hline \hline$s_{\mu}:$ & 0.999441703848 \\
$g_{\mu}:$ & 0.999733441115 \\
$c_{\mu}:$ & 1.116792453830 \\
\hline \hline
\end{tabular}

TABLE 4

MORTALiTy RATES.

\begin{tabular}{c|c}
\hline \hline Age $x$ & $\mu(x)$ \\
\hline 30 & $0.10 \%$ \\
40 & $0.18 \%$ \\
50 & $0.37 \%$ \\
60 & $0.88 \%$ \\
70 & $2.23 \%$ \\
80 & $5.74 \%$ \\
\hline \hline
\end{tabular}

\section{ACKNOWLEDGEMENTS}

We gratefully acknowledge the financial support of the "Communauté française de Belgique" under the "Projet d'Action de Recherches Concertées". We also wish to thank Andrew Cairns and the anonymous referees for their helpful comments.

\section{REFERENCES}

Blake, D., Cairns, A.J.G. and Dowd, K. (2003) PensionMetrics II: stochastic pension plan design during the distribution phase. Insurance: Mathematics and Economics 33(1), 29-47.

Davidoff, T., Brown, J. and Diamond, P. (2005) Annuities and individual welfare. American Economic Review 95(5), 1573-1590.

Devolder, P., Bosch, P.M. and Dominguez, F.I. (2003) Stochastic optimal control of annuity contracts. Insurance: Mathematics and Economics 33(2), 227-238. 
Devolder, P. and Hainaut, D. (2005) The annuity puzzle revisited: a deterministic version with Lagrangian methods. 15th annual international AFIR Colloquium, Zurich.

Fleming, W.H. and Rishel, R.W. (1975) Deterministic and stochastic control. Springer Verlag.

Fleming, W.H. and Soner, H.M. (1993) Controlled Markov processes and viscosity solutions. Springer Verlag.

KAPUR, S. and ORSZAG, M. (1999) A portfolio approach to investment and annuitization during retirement, Working paper Birkbeck College London.

KushneR, H.J. and DupuIS, P.G. (2001) Numerical methods for stochastic control problems in continuous time. Springer Verlag. Second edition.

LACHANCE, M. (2003) Optimal investment behavior as retirement looms, Working paper, Wharton School, University of Pensylvania Philadelphia.

Merton, R.C. (1969) Lifetime portfolio selection under uncertainty: The continuous-time case. Review of Economics and Statistics 51, 247-257.

Merton, R.C. (1971) Optimum consumption and portfolio rules in a continuous-time model. Journal of Economic Theory 3, 373-413.

Merton, R.C. (1990) On consumption-indexed public pension plans, in Bodie Z., Shoven J. (eds.), Financial aspects of the US pension plan system, University of Chicago Press, Chicago, 1983. (Reprinted as chapter 18 of Merton R.C. "Continuous time finance", Blackwell, Cambridge, MA.

Milevsky, M. (2001) Optimal annuitization policies: analysis of the options. North American Actuarial Journal 5(1), 57-69.

MilevsKy, M. (1998) Optimal asset allocation towards the end of the life cycle: to annuitize or not to annuitize?. The Journal of Risk and Insurance 65(3), 401-426.

Milevsky, M. and Young, V. (2003) Annuitization and Asset Allocation. Working paper. Individual Finance and Insurance Decisions Centre Toronto.

Petrova, P. (2004) The annuity puzzle gets bigger. Working paper Boston College.

PurCal, S. and PigGotT, J. (2004) Explaining annuity demand in Japan: an optimising approach. 8th congress on insurance: Mathematics \& Economics. Rome 2004.

PuRCAL, S. (2004) A stochastic control model for individual asset-liability management. 14th annual international AFIR Colloquium, Boston.

RichARD, S. (1975) Optimal consumption, portfolio and life insurance rules for an uncertain lived individual in a continuous time model. The Journal of Financial Economics 2 187-203.

YAARI, M. (1965) Uncertain Lifetime, Life Insurance and the theory of the Consumer. Review of Economics Studies 32(2), 137-150.

\section{DONATIEN HAINAUT}

Université Catholique de Louvain

Institute of actuarial sciences

Rue des Wallons, 6

B-1348, Louvain-La-Neuve

Belgium

E-mail:hainaut@actu.ucl.ac.be

Pieter Devolder

Université Catholique de Louvain

Institute of actuarial sciences

Rue des Wallons, 6

B-1348, Louvain-La-Neuve

Belgium

E-mail:devolder@actu.ucl.ac.be 